\title{
Conceptualizing for Educational Work Organization in Institutions of Higher Education: Mission, Goals, and Pedagogical Strategies for Reforming Higher Education in Kazakhstan
}

\author{
Saltanat Tazhbayeva
}

PhD of Pedagogy, Abay Kazakh National Pedagogical University

Meruert Assilkhanova

PhD of Pedagogy, Abay Kazakh National Pedagogical University

Lyazzat Ilimkhanova

PhD doctoral candidate, Independent Scientist - researcher, Email:lyazzat.ilimkhanova@gmail.com

Doi:10.5901/mjss.2014.v5n20p2738

\begin{abstract}
This article presents concepts underlying the organization of the educational process in institutions of higher education in Kazakhstan. The project is part of systemic educational reform efforts in the face of recent, profound socio-political changes in the nation. The project focuses specifically on the value of training future teachers through extracurricular activities and argues that such training effectively forms the professional qualities needed by high-quality teachers-abilities to implement active learning, democratize the learning process, and develop the nation's cultural and national mentality, among others. The research used a variety of methods to develop a model for this type of teacher training and reports the results of the model's implementation, partially in comparison with practicing teachers. The model is found to be effective, and its implementation within the university's framework is carefully detailed. Included is the overall conceptualization-the mission, goals, and educational strategies-needed for 21st-century higher education in Kazakhstan. The main orientations of educational work is highlighted-formation of ethical personal and professional qualities; of Kazakhstani patriotism, citizenship, and cultural identification; of morality and tolerance in the face of multiculturalism; and training for a healthy lifestyle.
\end{abstract}

Keywords: Extracurricular activity, teacher training, teacher traits, teacher quality, active learning, higher education

\section{Introduction}

In efforts to counteract the radical social changes and subsequent social issues Kazakhstan has endured at the turn of the 21st century, reform in higher education is being undertaken as one method of influencing the positive formation of a new Kazakh citizenry. In other words, the need for educational reform stems from the need to form a positive mentality of the individual and thus the mentality of the larger society, in a spirit of universal values that will help find ways to overcome the incompatibility of individuals and nations. This paper aims, therefore, to re-conceptualize the mission, goals, and pedagogical strategies in institutions of higher education by defining the main directions needed in Kazakhstan today. This paper also reflects basic conceptual approaches of the complex program of education in the Republic of Kazakhstan. Specifically targeted are problems in the spiritual and moral spheres of society and, consequently, in the educational system. The ideological vacuum—caused by changes in the social system, the abolition of Soviet ideological institutions, "wild" market relationships diluting the moral principles of society, the influence of the media (some of which understand freedom of expression as permissiveness)-has allowed the spread of anti-human ideas, views, and occurrences (e.g., drugs, alcohol, sexual promiscuity, self-centered pragmatism, cynicism, aggression) that negatively affect our youth. One solution to these problems is to find new approaches to the educational processes at universities called to train, educate, and develop the younger generation.

The final conceptualization of university mission, goals, and pedagogical strategies is presented near the end of the paper and consists of the following sections:

1. Purpose and objectives of the conceptualization. 
2. Some tendencies in the spiritual and moral development of students.

3. Purpose and objectives of higher education.

4. Principles of higher education.

5. Organizational model of educational work at the university.

6. Pedagogical conditions at the university.

7. Content of education at the university.

8. Educational Work Management at institutions of higher education.

\section{Theory and Methods}

Analysis of the theory and practice of teacher education and government documents on educational-system reform indicate that teacher training should also be reformed, so that it focuses not only on subject-based competencies but also on general cultural and methodological practices. The future teacher must also possess certain professionally relevant qualities or traits. Along with the educational process, university extracurricular activities for future teachers are very important to a high quality of teacher preparation.

In fact, the data indicate a lack of preparedness by secondary-school teachers for practical implementation of students' extracurricular activities. According to our observations, both students and teachers clearly express a close relationship between extracurricular activities and improvement in the quality of educational training. Ultimately, the professional and personal qualities of both students and teachers are very important influences in improving student performance (Tazhbayeva, 2000). During high school, with positive socialization and participation in voluntary associations, art groups, and so on, students acquire the firm landmarks, interpersonal skills, and professional and personal qualities necessary to develop skills in chosen fields as scientists, leaders, and public figures. It then follows that the university should also strive to create the best educational environment for holistic self-realization by students. Because we believe that university extracurricular activities are a factor of socialization containing the deepest possible formation of professional and ethical qualities of future teachers' personalities, we concentrated research in this area.

Thus, based on the established model of the organization of extracurricular activities of future professionals, we developed a comprehensive university training program, which takes into account not only how students want to see the teachers but also how young people would like to see themselves. The program was in the period from 1997 to 2006 in Aktobe State University after K. Zhubanov, and successfully been implemented in KazStateFemUni in the 2001 academic year, and is currently in use in the educational process at the Department of Pedagogy KazNSU named after Abay for training undergraduates.

Implementation of the proposed models in the practice of education and personal development in higher education requires coordination at all levels. Implementation, thus, required compliance with a number of pedagogical conditions, including:

- Establishment of student-oriented activity approaches for the organization of students' extracurricular activities (e.g., student government, small-group work, missions for the practical and/or creative nature).

- Professional and pedagogical orientation content of extracurricular activities for future teachers.

- Communications with schools and other institutions (e.g., orphanages, homes for the elderly, sports organizations) to establish extracurricular activities for university students.

- Coordination among all university sections, incumbent upon the Council on Educational Work created by the pro-rector. The council's task is scientific research, organization, and implementation of extracurricular educational work, as well as the experimental treatment of the strategy, methods, and results of education and educational work in the university departments.

We have included in the Council on Educational Work representatives of the pedagogy, philosophy, psychology, and physical education departments; the Vice Deans for educational work; representatives of libraries; dormitory commandants; chairman of the student council; and the heads of the permanent creative teams. The main activities of the Council are:

- Providing comprehensive current and future planning of extracurricular activities.

- Monitoring implementation of the extracurricular activities plan and the students' interests and values.

- Methodologically and practically supporting students' cultural and leisure activities.

- Coordinating university extracurricular work with the city and regional youth department.

- Coordinating extracurricular activities in student dormitories.

- Organizing the first courses of training supervisors and deputy deans of educational work on the organization 
of students' extracurricular activities.

We especially focused our development work on organizing sports and recreation activities in the hostel. In the dormitories of the physics, mathematics, and music pedagogical faculty, we have systematically conducted morning exercises, and the students actively attended various sports clubs and groups. We have attracted students to sports and helped them form positive habits of sport and recreational participation, personal hygiene, and managing their free time, including preparation for fulfilling their professional duties (Tazhbayeva, 1999).

The above theoretical and methodological basis for the organization of students' extracurricular activities, a model we developed, as well as the pedagogical conditions for its implementation were the basis of the experimental work, in which the technique was tested organizing extracurricular activities of students in professional training in higher educational institution. After setting out the theoretical basis for students' extracurricular activities, the education and development by the university, its theoretical model, and a model of the professional and personal qualities of the modern teacher, let us go on to develop a diagnostic level of education for future teachers.

In this case, we have chosen a range of methods that adequately measure the desired qualities. Signs of the motivational component identified through interviews, questionnaires, essays, teacher observations, signs of substantial component-testing, ranking solutions, pedagogical tasks and situations, conversations, process-behavioral component, and studied traits were studied by observing the process of extracurricular activities such as curatorial hours, business games, debates, and workshops. In addition, everyday life (at home, in the dorm, at leisure) evaluation component and professional and personal qualities of students were revealed using evaluative maps, i.e., plans of self. We used complex diagnostic procedures with different variations for ascertaining and monitoring stages of the experiments.

\section{Results and Discussion}

To determine the initial state of the professional and personal qualities of future teachers, we conducted an experiment using the set of diagnostic methods described above. The data in Table 1 indicates a low level of professional and personal qualities, which affects the quality of professional and educational training.

Table 1 - Initial levels of students' professional and personal qualities in the organization of university extracurricular activities

\begin{tabular}{|l|c|c|c|c|}
\hline \multirow{2}{*}{ Students } & \multicolumn{4}{|c|}{ Levels in Percentages } \\
\cline { 2 - 5 } & Low & Medium & Good & High \\
\hline Experimental group & 45 & 35 & 10 & 10 \\
\hline Control group & 26,5 & 50,1 & 13,4 & 10 \\
\hline
\end{tabular}

Along with this, we also identified the levels of the studied traits in teachers already working in schools. The data obtained are presented in Table 2 (Tazhbayeva, 2000).

Table 2 - Initial levels of professional and personal qualities of teachers

\begin{tabular}{|l|c|c|c|c|}
\hline \multirow{2}{*}{ Analysis group } & \multicolumn{4}{|c|}{ Levels in Percentages } \\
\cline { 2 - 5 } & Low & Medium & Good & High \\
\hline Pre-graduation years & 45 & 35 & 10 & 10 \\
\hline Graduation & 34,1 & 41,9 & 15 & 10 \\
\hline School teachers & 24,6 & 45,8 & 17,8 & 10,4 \\
\hline
\end{tabular}

The theoretical positions taken and the experimental data gathered determined the long-term direction of the formative experiment-an organized, comprehensive program of modernized student extracurricular activities, with the goal of forming certain traits needed by successful teachers. In this process, we found that professional and personal development includes two types of readiness: the first involves content and information readiness as well as moral, psychological, and operational-activity readiness. The second concerns readiness for professional-value orientations, professional consciousness, creativity, and self-development.

During the experimental work, we prepared and used the following courses: "The classroom teachers' activities for student moral education" as well as author and curriculum "Education of future teachers," "Preparing future teachers to morally educate pupils," "Form-master," "Conducting educational work at higher and special education institutions," 
"Preparing future teachers for educational technology school processes," "Theory of education and educational technology at the university," "The concept of education in high school," "University supervisors' use of technology for students' healthy lifestyles," "Class work," "Fundamentals of pedagogical skills," and others.

In Table 3, the program for modernized extracurricular training of future teachers is presented in a phased structure-content model (Tazhbayeva, 2000).

Table 3 - Structure-content model for training future teachers in extracurricular activities

\begin{tabular}{|c|c|c|}
\hline Stage & Goals and Objectives & Activity - Content \\
\hline $\begin{array}{l}\text { 1. Preparatory } \\
\text { Train supervising assistants to } \\
\text { organize and plan } \\
\text { extracurricular activities of } \\
\text { students in the group }\end{array}$ & $\begin{array}{l}\text { Prepare the conditions and means to } \\
\text { modernize extracurricular activities in the } \\
\text { educational system }\end{array}$ & $\begin{array}{l}\text { Prepare the concept and program for student education } \\
\text { and the legal documentation, in accordance with the } \\
\text { material base and additional financial support. } \\
\text { Hold a special seminar with teachers: "Scientific basis for } \\
\text { the organization of extracurricular activities for future } \\
\text { teachers." Arrange for supervisors methodological } \\
\text { seminar "Technology of the educational process at the } \\
\text { university." } \\
\text { Prepare a system of student self-government through a } \\
\text { combination of state and public forms of governance }\end{array}$ \\
\hline $\begin{array}{l}\text { II. Formative } \\
\text { Develop the program of } \\
\text { extracurricular activities }\end{array}$ & $\begin{array}{l}\text { Implement of the concept of the program } \\
\text { of education in the practical work and the } \\
\text { educational system in the excretion level } \\
\text { of stable system operation. }\end{array}$ & $\begin{array}{l}\text { Conduct with first-year students educational activities } \\
\text { aimed at the motivational orientation of future teachers. } \\
\text { Include students in self-government. } \\
\text { Include all Teaching and Support Staff in the operation } \\
\text { and management of the educational system }\end{array}$ \\
\hline III. Adjustment & $\begin{array}{l}\text { Changes in the concept and program of } \\
\text { education of students in extracurricular } \\
\text { activities. } \\
\text { Improvement of students in the group, } \\
\text { transforming it into a full self-government }\end{array}$ & $\begin{array}{l}\text { Conduct educational activities with students according to } \\
\text { the comprehensive plan } \\
\text { Implement relationships with community organizations } \\
\text { and cultural and educational institutions. Conduct } \\
\text { educational activities outside the university. } \\
\text { Exchange experiences in development of the educational } \\
\text { system within the institution in open forums (debates, } \\
\text { workshops, seminars, conferences, and print). } \\
\text { Improve the structure and content of activities of the } \\
\text { student government }\end{array}$ \\
\hline IV. Final effective & $\begin{array}{l}\text { Improve the educational process system } \\
\text { in all governance structures concerning } \\
\text { university extracurricular activities } \\
\text { Monitor the educational system and } \\
\text { training of teachers }\end{array}$ & $\begin{array}{l}\text { Develop the public governance system through } \\
\text { advanced functions of public administration entities } \\
\text { Prepare diagnostic evaluation techniques; } \\
\text { implementation them; process, analyze, and integrate the } \\
\text { resulting data }\end{array}$ \\
\hline
\end{tabular}

At the preparatory stage, certain conditions and means for implementation of the modernization student extracurricular activities included organizational issues-creating the Council on Educational Work and familiarizing its members with the program of university extracurricular activities-the coordination with professors through seminars on teaching departments, for instance, "The scientific basis for the organization of extracurricular activities for future teachers." Facilitators held a methodological seminar, "Technology of the university educational process." At this stage, the work involved students, that is, in the prospects of improving student extracurricular activities and in working with members of the student government (in the faculty and student dormitories). A number of activities took place with first-year students, for example, "Teacher, to the name of your ..."; "Press Conference"; and "Information curatorial hour." A special role in this and subsequent stages was assigned to the psychological and pedagogical disciplines, and professors became involved in the implementation of the new program. Thus, in the preparatory phase, potential organizational problems, for instance, motivating the participants-students, teachers, supervisors, administrative employees, and deans-were solved.

In the second or formative stage, the modernization of student extracurricular activities was conducted during a long period covering the activities of first-, second-, and third-year students. This development of extracurricular activities for future teachers included a variety of activities in all areas of education as outlined in the model (Figure 1). Special attention was paid to the organization of activities for professional orientation, e.g., meetings with teachers, innovative 
schools in Almaty, "Educational Olympics," competitions among form-masters. In this case, the students' attention was drawn to the moral and ethical qualities of a future teacher (expert model, Figure 1). Significant efforts advocated sports and recreational activities and leisure in the dormitories, e.g., morning gymnastics, sports groups and clubs, parties, meetings with interesting people: masters of sports, writers, actors (Tazhbayeva, 2000). Throughout the experimental work, a positive psychological climate in student groups was formed. In groups, curators and teachers administered sociometric measurements of interpersonal relationships, both formal and informal leaders, and based on these data, a collaboration of students.

In our experiment, the form of students' extracurricular activities was not fundamentally new or original. However, we wanted to inculcate in students a new meaning, in accordance with modern teaching requirements and interactive methods of conducting activities, e.g., games, debates, workshops, competitions, research projects. Throughout this activity, the second stage of the experimental work strengthened the future teachers' motivations and value orientation, their outlook, their Kazakh patriotism and citizenship, expanded the essence of their moral and ethical concepts, formed appropriate experiences, reflection, self-assessment, and on this broad basis, they become attached to self-education and lifelong learning (Tazhbayeva, 2000).

In the third or adjustment stage, corrective work to the program occurred, and the student activity programs expanded their borders. In close connection with practice teaching, students conducted educational activities with school students, organized campaign-"landing" in the little ones at home, orphanages, and homes for the elderly. Future teachers became involved as mentors or assistant curators to work with first-year students, with coaches and sports clubs, and a myriad of other activities. Through the analysis of such activities, we can assess students' education and to some extent, their willingness to work as a teacher. (Tazhbayeva, 2001)

In the final effectiveness stage, the program for training future teachers in extracurricular activities implementation continued. However, the focus was on determination of the results of all previous work, although the "slices" of the program continued to be conducted after each of the stages). To identify the impact of this work, it was applied with some adjustments as a diagnostic technique, as when ascertaining the experiment itself (Tazhbayeva, 2001).

The results of this experimental work were compared with the initial level of future teachers' professional and personal qualities to draw conclusions about the effectiveness of our proposed program. This information is presented in Table 4. (Tazhbayeva, 2001)

Table 4 - Levels and stages of professional and personal qualities of future teachers in experimental groups

\begin{tabular}{|l|c|c|c|c|c|}
\hline \multirow{2}{*}{ Levels } & \multicolumn{5}{|c|}{ Results of «Sections» in Percentages } \\
\cline { 2 - 6 } & Initial «Section» & First «Section» & Second «section» & Third «Section» & Final «section» \\
\hline Low & 45 & 45 & 32 & 26,5 & 15,5 \\
\hline Medium & 35 & 35 & 43,4 & 50,1 & 24,2 \\
\hline Good & 10 & 10 & 14,6 & 13,4 & 50,3 \\
\hline High & 10 & 10 & 10 & 10 & 10 \\
\hline
\end{tabular}

These results indicate that implementing a comprehensive program for training in extracurricular activities helps students develop higher levels of professional and personal qualities. These data are also reflected in Figure 1.

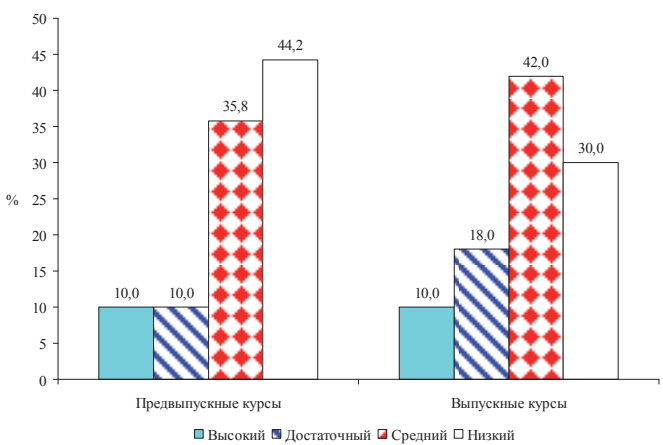

Figure 1 - The levels of formation of professional and personal qualities by future teachers in university extracurricular activities 
Comparison of the results between the experimental and control groups reveals that in the past, there has been growth in professional and personal qualities, but the changes have been very small. Advances to the good and high levels of desired qualities were not observed. In addition, summary data from the experimental group were compared with data from a similar survey of currently practicing teachers. They held special courses such as "Organization of the Educational Process in Schools," "The Use of Innovative Technologies in the Organization of School Extracurricular Activities." Analysis of the currently practicing teachers' data indicated that high and good levels of the desired qualities was reached, respectively, compared with the original data.

Thus, as the experiment indicates, we saw steady growth in the professional and personal qualities of future teachers. Therefore, the proposed methodology for organization of extracurricular activities is effective and can be recommended for implementation in the university's educational process (Tazhbayeva, 2002).

We believe that university extracurricular activities are a factor of socialization containing the deepest possible formation of professional and ethical qualities of future teachers' personalities in the following relationships: teacher $\leftrightarrow$ student, teacher $\leftrightarrow$ student team, student $\leftrightarrow$ student, student $\leftrightarrow$ student team. These communication relationships can become professional and ethical if the candidate possesses the following:

- A combination of personal and social goals and interests.

- A responsible attitude toward order.

- Rigor and integrity in relation to oneself and others.

- Organizational skills and self-discipline.

- The ability to cooperate, mutual control, and obedience.

- Acceptance of objective critical evaluation, willingness to participate in professional development and selfreflection.

An important area of preparing students for a healthy lifestyle is the organization of the curator of the student group. Graduates of pedagogical universities are working mainly in the education system -in kindergartens, schools and colleges. Curators actively target the students to act as an educator, practitioner, teacher, college professor, secondary and higher education institutions, to school sports and sports and recreational activities.

\section{Conclusions}

The results of many years of theoretical and experimental studies suggest the following conclusions:

1. We have defined the theoretical and methodological basis for research into extracurricular activities of university students. Strategic guidelines have been adopted: a theory of activity-systematic and structural, student-oriented, cultural, competency-based, integrative approaches-that enables future teachers to interact intelligently and complete tasks. The methodological guide for this model of student extracurricular activities is also the theory of holistic educational process.

2. The study outlines the theoretical basis of student extracurricular activities, which represent a subsystem of the pedagogical university's educational process, as well as the professional and personal development of future teachers on the basis of individual creativity. Extracurricular activities are a training process structurally similar to the theory of educational systems (holistic pedagogical process), including the functions of teachers and students, goals and objectives, means, forms, methods, and techniques.

3. These theoretical and methodological principles and the nature of extracurricular activities allowed us to develop a theoretical model of this subsystem of professional teacher education at the university, which includes the target set, the subjects of the educational process (students $\leftrightarrow$ teachers, $\leftrightarrow$ curators $\leftrightarrow$ administration staff), and educational technology. The center coordinating the student extracurricular activities is the Council on Educational Work.

The model of student extracurricular activities is related to the model of the specialist-the future teacher. This study represents one aspect of the model-educational (Tazhbayeva, 2002). We have studied a set of professional and personal traits of teachers (pedagogical, psychological, social, and ethical) to create effective, appropriate extracurricular activities.

4. The method for diagnosis of educating future teachers in the organization of extracurricular activities, which is adequate structural component of forming qualities of the teacher, was developed. We used a range of diagnostic methods (experimental, empirical, and theoretical): interview, questionnaire, essays, teacher observation, testing, ranking, solutions of pedagogical tasks and situations, interviews, observation, maps of self-education plans, the study of university records, and the advanced experience of pedagogical universities. 
5. There have been justified terms and forms of extracurricular activities of students, ensuring that they are brought up in an integrated training, including: special, purposeful training of university teachers to meet the challenges of educating students outside the classroom, including supervisors, managers, relationship of class and extracurricular activities, especially on psychological pedagogical and methodological aspects of the training, the integration of all areas of the organization of extracurricular activities, the establishment of the university management of the structural unit to the organization and coordination of educational work (advice on educational work), the development of the student government and student activities, the relationship with civil society and the cultural and educational institutions and schools, the continuity in the formation of professional and meaningful qualities of a future teacher (the continuity of research methods from stage to stage, from course to course), monitoring the education of students. During the experimental work, there were used both traditional forms of organization of student extracurricular activities (e.g., curator hours, evenings, holidays, contests, SSS), and interactive (e.g., debates, workshops, business games, educational centers, clubs). The greatest emphasis outside the classroom was on intercompany relationships and students living in a dormitory. Finally, the use of small-group and collective forms to create favorable conditions for students to cooperate helped to shape the future teachers' personal qualities.

6. Based on theoretical and methodological principles and on the results of experimental work, we developed concepts and scientific and practical advice on the organization of student extracurricular activities. "The concept of the organization of educational work in higher education" includes the goals and objectives of education of future professionals, the model of organization of educational work at the university, pedagogical conditions of university management, and educational work in the institution.

Thus, there have been solved tasks during the study, proved the hypothesis of research, which is an indication that the situation to be defended, justified and the objective of the work has been achieved.

\section{Recommendations}

Based on this study the following steps are recommended:

Integrated restructuring of the university's educational-process content. This restructuring should focus on disclosing the nature and characteristics of the object of professional activity, to form professionally significant qualities in future teachers

Practice of HEls regular scientific-practical seminar "Teaching technology in the educational process of the university," to improve efficiency in training university teachers on the organization of education in extracurricular activities

Establishment at universities' Institute for Advanced Studies a special course, "Scientific basis for the organization of education in HEI," especially for the vice-rector on educational work, deputy deans, and academic groups' curators

Appropriate use of comprehensive diagnostic techniques and the model of training in extracurricular activities developed in this research for the high-quality preparation of future teachers

The research we conducted is only one option of the modern approach to education and developmental tasks in higher education; thus, we do not claim that our solution is the most complete and comprehensive. We too await further research to improve students' educational, scientific, and research activities in pedagogical institutions of higher education in the Republic of Kazakhstan. We hope for further developments in connection with extracurricular activities that aim to help form a moral culture and the moral and ethical qualities of future teachers (Tazhbayeva, 2003).

\section{Mission, Goals, and Pedagogical Strategies}

\subsection{The purpose and objectives of the conceptualization}

Purpose of the conceptualization: to develop modern approaches for the organization of the educational processes of higher education.

Objectives of the conceptualization:

- Determine the goals and objectives of education at the university.

- Highlight the basic principles of higher education in accordance with present socioeconomic conditions.

- Develop a structural model of higher education to reflect its main directions.

- Determine pedagogical conditions necessary for the structural model to function effectively.

- Determine the content of the main directions of educational work at the university (Tazhbayeva, 2003). 


\subsection{Some tendencies in the spiritual and moral development of students}

Analysis of the situation in the student community reveals both positive and negative tendencies:

- Modern Kazakh students are a generation raised under the circumstances of market reforms and changed social relations, which could be reflected in their value orientations. Therefore, individualism, pragmatism, and the desire for material well-being, sometimes at any cost, dominate the environment.

- Young people tend to view participation in public life through the lens of their own interests and desires. They seem to have little awareness or understanding of political, economic, and socio-cultural processes affecting the fate of each of them.

- A certain strata of young people believe that quality education is a leading social value because it forms the basis for professional growth and, consequently, achieving material prosperity and high social status.

- New opportunities for personal development (e.g., a great flow of scientific and cultural information, computerization, study abroad opportunities) increase the number of creative, talented youth realizing their potential through various activities such as science, art, and sports.

- There is a tendency to create intra-high student youth organizations, movements, and associations, not for political purposes, but as future-oriented professional activities. Among the motives for creating and joining these organizations are interest in the selected area of activity and the opportunity to realize their potential and to express their views and beliefs.

- However, among young people, it is widely believed that "money talks," and students espousing this belief often put aside issues of quality of education as well as the need for their own efforts in this direction.

- Inter-ethnic relations on students' teams look stable.

- Stratification of young people is taking place: some, both boys and girls, prefer "a Western way of life," including a career, success in various spheres of life, a higher social status, and material wealth. Others prefer to increase the importance of traditional religious values in everyday life; the number of believers has tended to increase among students.

- Significant numbers of young people are characterized by possessing a low level of general culture and all its components (e.g., moral, legal, political, everyday life culture, communication culture).

- Young people's health is declining because of increased drug addiction, alcoholism, and spread of venereal disease (Tazhbayeva, 2003).

\subsection{Purpose and objectives of higher education}

The current state of our society - the processes taking place in the political, economic and cultural life of our countryencourage a fresh look at the problem of educating our citizens and of forming the intellectual and creative potential of individuals in higher education. Just because passing a school of public organizations, associations, art groups, and students gain a solid life guidance, interpersonal skills and personal qualities necessary for a specialist in a chosen field, scientists, leaders, public figures. Hence, along with addressing issues of educational process, the university must also endeavor to create conditions for self-development and self-assertion of the individual, that is, holistic improvement of students. Defining goals, objectives, content of educational work with students was based on such methodological ideas as the idea of the integrity of the educational process, its subject character, personality-active approach to the educational process. The socio-political conditions of Kazakhstan cause issues of citizenship and patriotism to be particularly important. Under these particular circumstances, the application of this concept is fundamental to forming professionally significant individual qualities and to a healthy life for the younger Kazakh generation. On the assumption of abovementioned, education at the university is a joint activity of professors and students in the educational process, aimed at the establishment of beliefs, morals, and general cultural and professional qualities that may be realized in students who become lifelong learners.

Achievement of this goal involves creating a university environment that fosters a relationship between the student and the university such that the student's entire personality is positively affected by higher education. A humanitarian culture and environment at the university manifests in an atmosphere of trust, cooperation, and co-creative exploration by professors and students, to provide well trained, high-quality specialists. Such characteristics are essential for implementing effective academic and extracurricular activities at the university. Overall, higher education encourages the joint pursuit by students and professors of the socially and professionally significant qualities of a future professional and a Kazakh citizen. 


\subsection{Educational objectives of the university:}

- Analysis of the professional and personal needs and interests of students in the new socioeconomic conditions.

- Organization of needed educational content, including moral education.

- Formation of Kazakh citizenship and patriotism as relevant to the individual's present moral qualities.

- Establishment of conditions for the development of student autonomy and personal and social activity, to include the organization of effective student government.

- Dissemination of information and tools whereby students may form a healthy life in both academic and extracurricular activities and gain an environmental education.

- Implementation of a wide range of cultural activities, to include the formation of multicultural identity in training and extracurricular activities.

- Creation, cultivation, and maintenance of positive traditions of the university.

- Research and implementation of new, diverse forms of educational work outside the classroom.

- Lecturers training for the implementation of the educational aspect in the process of learning and extracurricular educational work (Tazhbayeva, Kalieva, 2005).

\subsection{Principles of higher education}

In general, the principles of education are the main provisions, ideas determining content, organizational forms, and methods of the educational process in accordance with the school's common laws and goals. Under present socioeconomic conditions, the topical principles in institutions of higher education include the following (explained below):

1. Emphasis on social and nation needs in Kazakhstan.

2. Unity of education and training.

3. Humanistic educational direction and the personal approach.

4. Democratization of the educational process.

5. Active approaches to learning.

6. Educational impact of the collective.

7. Cultural conformity and the cultural orientation of teaching.

8. Uniform requirements of students by teaching staff.

\subsubsection{Emphasis on social and national needs in Kazakhstan}

This emphasis indicates a correspondence between the character and content of education to the social needs and the interests of the country and the people. Presently, activities should be subject to the main objective of higher educationa formation of morally mature, socially active, professionally competent individual, capable of self-development. The current requirements to the specialist-graduate to form professionally significant qualities of the individual.

\subsubsection{Unity of education and training}

Teaching and education processes are difficult to separate in thought and in practice because they represent holistic educational processes and are based on common pedagogical principles. Unifying education and training is particularly challenging in terms of integration of principles based on the activity, individual teaching approaches, and humanization of pedagogical process. Since professors tend to concentrate on subject-content rather than pedagogical methods, teaching can become the weakest link in the educational institution. Therefore, especially important is the organization of pedagogical theories and methods.

\subsubsection{Humanistic educational direction and the personal approach}

This approach involves the humane treatment of the individual student, taking it as a given for professor. Based on this, we must proceed in education from the interests, skills, and capabilities of a student to respect his right and dignity, have reasonable and feasible requirements, on the basis of the positive qualities of his nature, develop them, and encourage self-discovery and self-education. 


\subsubsection{Democratization of the educational process.}

This concept basically indicates a cooperative relationship, a partnership of professor and student, and the recognition of the student as the subject of the education process. Democratization of the process avoids giving educational interactions a "hidden" nature; it also avoids peremptory or authoritarian pedagogical influence.

\subsubsection{Active approaches to learning.}

The efficiency of education and the formation of socially and professionally significant qualities of the person is due to the degree of active participation in various activities (academic and extracurricular), the content of activities and lessons, methods of organization, and motivations for participation.

Extracurricular educational activities are necessary to the students' future professional activities.

\subsubsection{Educational impact of the collective}

Conditions necessary for the formation of personal qualities of the future specialist are created in the team, in terms of communication, when the student has the opportunity to engage in a variety of relations with other course participants: business, personal, intellectual, educational, employment, self-activity-creative, and so on. At the same time, this situation creates conditions for the formation of an active life for the individual. Acquiring an active life of citizenship requires experience of public life and civil development. In this process, a significant role is played by bodies of student government emerging at a certain stage of the collective's development. Forming and fixing all the positive traditions of this collective then become important.

\subsubsection{Cultural conformity and the cultural orientation of teaching.}

These concepts involve formation of various aspects of culture based on knowledge of the individual's national culture and other cultures; the development of patriotism, public spirit, historical memory; the formation of national selfconsciousness and tolerance.

\subsubsection{Uniform requirements of students by teaching staff.}

This principle shows such natural law of educational process as the integrity of the educational influences, which is ensured by consistency in teaching requirements and unity of the declared social attitudes and real actions of lecturers ( Tazhbayeva, Shakiyeva, and Abildayev, 2005).

\section{Organizational Model of Educational Work at the University}

In this model (Figure 2), the systemic proposed approach is shown based on defined goals and objectives of four key directions of university educational work, which is conducted in each direction, both during class hours and extracurricular time. Rigid forms of selection in a particular direction are not feasible, since each direction allows more than one educational task 


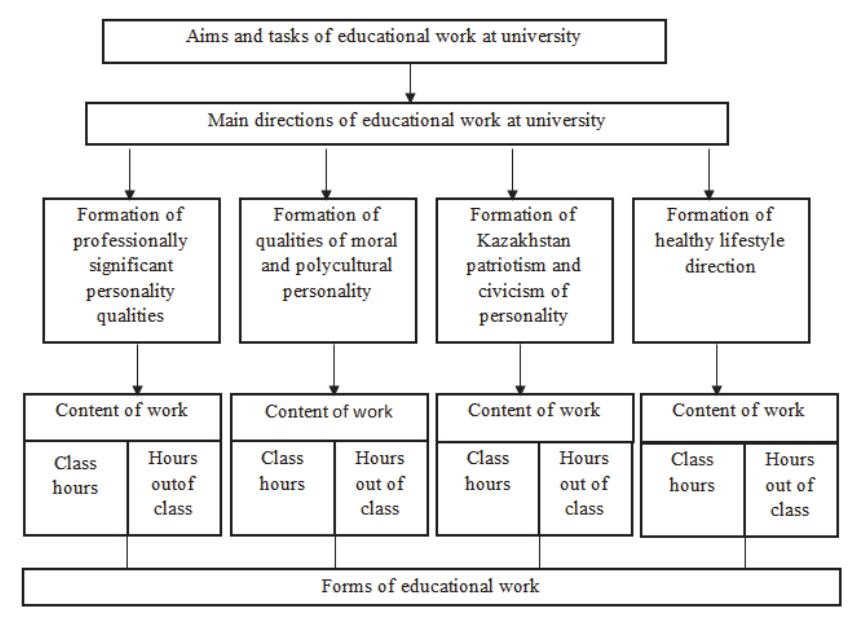

Figure 2 - Organizational model of university educational work

\section{Pedagogical Conditions of the Educational Work at the University}

In the conditions of university educational work should be included two main components-social relations and the physical environment.

\subsection{Social relations}

- Reviving a genuine culture of communication, an atmosphere of genuine respect for the individual; this involves overcoming authoritarianism in relation to the students by the administration and faculty.

- Creating opportunities for choosing an educational path in introduction of credit technology of education.

- Introducing elements of persuasive learning: using discussion techniques with the material, conclusive presentation of educational material, providing students with information on alternative approaches to a problem, providing opportunities to explore these approaches and others.

- Creating conditions for active realization of personality: conducting various art competitions and creative projects, encouraging originality and creative expression by students.

- Publicizing discussions of issues and problems in higher education.

- Participating in the actual functioning of the student government, during which process students experience practical acquisition of democratic procedures.

- Encouraging critical and constructive suggestions from students on various aspects of the educational institution.

- Introducing students to art: informal competitions, festivals, concerts, parties, exhibitions of their own work; attending concerts, performances, exhibitions; creating clubs, hobby groups, discussion of cultural events.

- Creation of student media (university, faculty news and papers presented on educational television).

- Actualizing the educational potential of the individual professor.

- Offering competitions: "Supervising professor of the Year," "Professor of the Year," and so on. Encouraging professors who participate in the competitions.

\subsection{Physical environment}

Creating comfortable, health conserving environment for learning activities of students and professors:

- Correspondence of school premises and equipment to health and safety standards and requirements.

- Aesthetic appearance of classrooms, hallways, and other areas of the university.

- Availability of necessary support units in educational buildings (recreational locations, dining rooms, cloakroom). 
To keep the physical environment in good condition and to train students through work to form their culture of life, students should perform tasks to maintain order and cleanliness on the premises and at the university, introduce certain rules, and monitor their behavior (for example, a ban on smoking on campus).

\section{Content of Educational Work in Higher Education}

A young specialist of the 21st century is a broadly educated, non-standard thinking, open-minded professional, civically active, and spiritually, morally, and professionally prepared to work in a chosen profession. He must know his own value in the labor market and be capable, if circumstances require, of freely changing specializations in a particular direction of the university. He must be psychologically prepared to build interpersonal relationships, to respect the opinions of others, be tolerant, and be capable of finding solutions in complex industrial and domestic conflicts. His main capital-a highly developed sense of responsibility to society, the family, the collective, and himself.

In this regard, the young person must be able to do the following:

- Adapt to changing conditions of life and focus on the social and political situation, based on one's attitudes, beliefs, ideals, and humanistic values.

- Possess a national consciousness and patriotism, qualities of citizenship, the desire to participate in the formation of the Republic of Kazakhstan as a secular, legal, economic and cultural state with a significant place in the world.

- $\quad$ Respect the law and possess social responsibility, civil courage, inner freedom, and dignity.

- Practice objective self-evaluation and self-development, realize one's potential (capabilities, possibilities) and try to implement it and progress; make independent decisions; be highly motivated and enterprising.

- Have a high level of social activity in all spheres of life, the desire to seek the new; find creative solutions to personal and professional problems; compete in socioeconomic activities.

- Practice compassion, tact, and personal integrity; exclude intolerance and hostility to those of different nationalities and religions, and to dissidents.

- $\quad$ Recognize the value of one's health, a non-renewable resource of life.

- Become initiated into and realize the value of national culture and the world.

Based on these abilities, the main directions of educational work at the university should include efforts to form the following personal qualities (discussed below):

1. Professionalism

2. Morality and tolerance within multiculturalism.

3. Kazakh patriotism and citizenship

4. Willingness to maintain a healthy lifestyle

\subsection{Professionally significant qualities}

In the training for each specialty should be elucidated the specific professional qualities needed. However, the major personality qualities that determine success in learning a profession, in the formation of the individual as an expert, are the desire to know, the ability to learn, and the capacity for creative solutions to professional problems.

The implementation of this direction during class hours is the organization educating, developing education, i.e. persuading education. To this end are used innovative technologies, and active learning (e.g., problem-based instruction, collective creativity, discussion and debate, brainstorming, training, game design, simulation games), in which learners through their own efforts gain new knowledge. Herewith students form productive communication, organizational, and analytical skills, including the ability to find ways and means for answers or solutions, including the non-traditional. It can be useful to encourage competition, which allows applying game techniques to the learning process and makes the learning process more emotional. Different forms of teaching and research work, forming the research culture of the student, play an important role in the development of personal qualities.

During extracurricular hours, the formation of professionally significant qualities happens when students participate in various forms of research. It is necessary to conduct such special courses as "Culture of intellectuals," and "Students' research culture" (if it is not included in the curriculum.) In these special coursers, students learn skills from scientific literature (by searching for information, reading, annotating, note-taking, abstracting, and reviewing), thus learning labor skills and the production of their own texts. The organization of various art competitions, contests, and events related to students' future careers helps develop their creative abilities. 


\subsection{Moral traits and multicultural identity}

This process is conducted during class hours in two ways: 1) accumulation of moral experience in communicating with the professor; 2) assimilation and moral awareness of the content of social sciences and humanities disciplines (e.g., ethics, aesthetics, pedagogy, psychology, cultural studies, languages) in different forms (e.g., conversation, discussion, creative work).

It is difficult to overestimate the role of the professor in the education of students. Educational effect shows the following qualities of the professor in its manifestation: accuracy, courtesy, neatness, speech culture, erudition, exactness, coherence, and consistency in requirements, responsibility, fairness in assessment, the desire to encourage the student, a sense of humor, honesty, and scruples. To be a professor in the true sense of the word, not just a narrow professional, professors should create learning situations. During class hours, a special course can be offered a for students on "communication culture" or "the basics of self-development," where students are introduced to the concepts of self-development, self-knowledge, self-evaluation, temperament, character, emotions, and empathy as means of understanding the other person. Students also learn through training the basics of managing their emotional and mental states, ways to resolve interpersonal conflicts, and other strategies to ensure professional conduct. During extracurricular hours, various forms of educational work can be used: the supervising professor hours can be devoted to ethical issues, art, national culture, or other topics of interest. Other forms of educational work include ethical theater, evening or holiday events, clubs for the quick-witted, quizzes, festivals, concerts, workshops, and special-interest clubs.

\subsection{Kazakh patriotism and citizenship.}

During class hours, this direction is realized primarily in the acquisition of moral awareness in social science and humanities disciplines: history, philosophy, political science, cultural studies, area studies, and language courses. Educational activities such as discussion, dispute, debates, role-playing and "round table" are particularly in demand.

Such forms of work with students allow them not only to obtain knowledge of their motherland, bright moments of its history, prominent personalities, culture, and art but also to experience vivid emotions springing from interesting excursions, meetings with prominent personalities, cultural and art workers; hiking, local history work; festivals, contests, concerts, national holidays; clubs for art lovers, watching certain shows, movies, and more contribute to the patriotic education of the individual outside the classroom.

\subsection{Willingness to maintain a healthy lifestyle}

During class hours, the most serious attention should be given to the organization of the health-learning environment: e.g., meeting the health standards training facilities and equipment, rational curriculum schedule. University physical education classes will become effective only when they are no longer formal "classes to be passed," but are actually attractive to students.

Outside the classroom, sports organizations of the institution (sections, clubs) and an informal organization of student leisure activities (e.g., events, hiking, weekend trips, student summer camps) take priority.

At the same time, it is necessary to help students form special knowledge and certain skills for a healthy lifestyle. This effort should include programs for the prevention of alcoholism, drug addiction, and smoking, for example. Activities should include prevention training, role playing, and other activities conducted with the assistance of physicians, psychologists, and other professionals.

\section{Educational Department at the University}

Implementation of the proposed model at the university may be assigned to the Council on Educational Work, created by the pro-rector on educational work.

The Council on Educational Work is the main collective body, composed of representatives of the following departments: pedagogy, philosophy, psychology, physical education, deputy deans of educational work, representatives of student organizations, and heads of permanent creative teams. The Council performs long-term integrated planning and has a coordinating function that monitors the implementation of plans and interests, value orientations for students, methodological and practical support for organizing cultural and leisure activities, coordination of educational work with the departments of the University for Youth under the administration of the city and the region, the organization of firstyear students supervising professor study, and the Vice Deans on educational work. For the organization of this work, a 
social and administrative unit of the university had to be created. In addition, the Council coordinates and directs the work of the Faculty Council, created by the deputy dean of educational work. The Board of the Faculty of educational work includes representatives of departments, supervisors, and representatives of student government organizations.

Creating a professional structure, organizing and coordinating extracurricular activities, is one of the main conditions to ensure its effectiveness. Another important condition for the efficiency and viability of the proposed system of educational work is the development of student's government and student activities, organizational forms, which may be very different: the Student Council in the dorms, monitor department, creative community of interests that are created to solve a particular problem and needs of students in self-realization, Student Construction Brigade, sports club, Student Committee, Student Scientific Society, Association of Creative Teams. This concept represents one of possible approach to the implementation of such an important aspect of the educational process as an educational work at the university. For its implementation it is required appropriate training courses and programs (Tazhbayeva, 2005).

\section{Conclusion}

The university's Council on Educational Work coordinates and directs the Faculty Council, created under supervision of the deputy dean for development work. The Faculty Council includes representatives of the departments, tutors, and representatives of student organizations. The creation of this professional structure, which organizes and coordinates extracurricular activities, is one of the main components that ensures their effectiveness. Another important condition for the health and viability of the proposed system of student development is students' self-management authority and students' proactivity, organizational forms of which may vary: Student Council hostels, Starostat, creative community of interests that solve a specific problem and/or meet students' self-development needs, sports clubs, student support, and creative teams.

As a result of the theoretical and experimental research, we have clarified the phrase "extracurricular activities of students in institutions of higher education." This daily work of teachers and students focused on the formation and development of students' moral belief systems, common cultural, professional, and personal qualities that will be realized through continued self-education. This is one possible approach to implementing the university's very important, highquality development of future teachers. Its implementation requires appropriate training courses and programs.

\section{References}

Tazhbayeva, S.G. (1999). Education of a future teacher. Almaty: ASU named after Abay, 170 p.

Tazhbayeva, S.G., Kussainov, H.H., Terekova, F.E., Toretayeva, G.T. (2000). Organization of extracurricular activities of students. Almaty: KNPU named after Abay, $40 \mathrm{p}$.

Tazhbayeva, S.G. (2000). The use of innovative technologies in the professional preparation of teachers / / XXX Intern. Conf. Almaty: Kazakh State National University named after Al-Farabi, Part 1, 283-284.

Tazhbayeva, S.G. (2000). Trip to the world of Education. Almaty: "Kazakhstan school" journal, 3, 56-58.

Tazhbayeva, S.G. (2000). To educate future teachers for courtesy. Almaty: "Nation's example" journal, 2, 48-51.

Tazhbayeva, S.G. (2000). On formation and education of personality of youth generation. Almaty: "Nation's example" journal, 4-5, 117126.

Tazhbayeva, S.G. (2001). Organization of extracurricular activities with students in higher educational institutes / / Materials of the International. Scientific-practical conference. Conf. "Reformation of Higher Pedagogical Education in the modern conditions of social and economic development of Kazakhstan: experience, problems and prospects." - Atyrau: Atyrau. State. University named after Dosmukhamedov H., 389-393.

Tazhbayeva, S.G. (2001). Activities of the social teacher in formation of the personality of the pupil / / Materials of the International. Scientific-practical conference. "Pedagogical and legal problems of socialization of students." - Almaty: ASU named after Abay, 108-111.

Tazhbayeva, S.G. (2001). Organization of educational work in higher and special educational institutions. - Aktobe, 248.

Tazhbayeva, S.G., Praliyev, S.Zh., Kazmaganbetov, A.G. (2002). Education technology of a healthy lifestyle in the process of moral and volitional personality of students: method. textbooks. - Almaty: KazStateFemPU, $82 \mathrm{p}$.

Tazhbayeva, S.G. (2002). Willingness to school teachers and students in the formation of moral and volitional personality students in extracurricular activities / / Materials of the republics. Conf. "Theoretical and methodological basis of the modernization of the system of teacher education in the Republic of Kazakhstan" / IASP. - Almaty, S, 49-56.

Tazhbayeva, S.G. (2003). Preparing future teachers to technology educational process in the school: learning method. textbook. Almaty: KNPU named after Abay, $213 \mathrm{p}$.

Tazhbayeva, S.G. (2003). Model structure and activity in the general system of professional training / / "High school in Kazakhstan" journal, 4 (2), 40-43.

Tazhbayeva, S.G. (2003). Philosophical and psychological aspects of training future teachers of extracurricular activities / / Materials of 
the International. Conf. "Cooperation between universities in the 21st century." - Moscow: Moscow State University. University, 310-313.

Tazhbayeva, S.G., Kalieva, G.I. (2005). The concept of the organization of educational work in higher education. - Almaty: KazSPU named after Abay, $62 \mathrm{p}$.

Tazhbayeva, S.G., Shakiyeva, L.B., Abildayev, E.S. (2005). Scientific basis for education of students in the activity of supervising professor (method. materials). - Almaty: KazStateFemPI, 34 p.

Tazhbayeva, S.G. (2005). Analysis of the results of the work done in preparation of future teachers in extracurricular activities of the university / / Materials of the Third Intern. Scientific Conf. "Integrative function of pedagogy in the international educational space" / IASP. - Moscow, Warsaw, 17-21. 